\title{
Accountability as a general function of language
}

\author{
JANN SCHEUER
}

The article discusses the concept of accountability. The general assumption is that accountability is a primal concern in language and language use. The point of departure is Harold Garfinkel's definition in Studies in Ethnomethodology establishing accountability as a key notion in a pragmatist understanding of social life. The term designates the observation that social agents achieve their sociability by acting so that their doings display their own meaningfulness in a social context - thereby creating such a context (Garfinkel 1967). The concept is discussed in three distinctive areas of language study. First, it is demonstrated through an ethnomethodological approach that any form of communication is critically dependent on participants' mutual recognition of each other's accountability. Second, some key notions of conversation analysis are demonstrated to be functional in such a perspective. The aim is to demonstrate that the turn-taking mechanics of talk-in-interaction may be conceptualized as methods of constructing accountability. Third, it is demonstrated in a functional linguistic framework how speakers' accountability is fronted in Danish sentences by such means as word order and the use of a particular paradigm of sentence adverbs. 